\title{
CRESCIMENTO POPULACIONAL, PAISAGEM E QUALIDADE DE VIDA EM POÇOS DE CALDAS (MG), UMA CIDADE MÉDIA TURÍSTICA
}

\author{
Alexandre Carvalho de Andrade ${ }^{1}$ \\ Giovanna Moraes Ramos ${ }^{2}$ \\ Raphael Miranda Martins ${ }^{3}$
}

\section{Resumo}

Poços de Caldas é um município localizado no Sul de Minas e tem população de 152.435 habitantes (IBGE, 2010). Desde o começo de sua formação como cidade, apresenta significativa importância da atividade turística, em especial devido as fontes de águas hidrotermais e sua paisagem montanhosa. Entretanto, em meados do século XX se iniciou um processo de diversificação e desenvolvimento da economia, o que favoreceu o crescimento populacional, a expansão urbana, e, por consequência, aconteceram diferentes impactos na qualidade de vida, na organização espacial e na paisagem local. Neste contexto, o presente trabalho tem como objetivo analisar a qualidade de vida em Poços de Caldas, por meio de indicadores quantitativos e da percepção de seus moradores.

Palavras-chave: Qualidade de Vida Urbana; Paisagens; Turismo.

\section{POPULATIONAL GROWTH, LANDSCAPE AND QUALITY OF LIFE IN POÇOS DE CALDAS (MG), A MEDIUM-SIZED TOURISTIC CITY}

\begin{abstract}
Poços de Caldas is a county located in the South of Minas Gerais and has the population of 152.435 inhabitants (IBGE, 2010). Since the beginning of its formation as a city, it shows significant importance due its touristic activity, especially because of its hydrothermal water sources and its mountainous landscape. However, in the middle of 20th century a diversification process started, what supported the populational growth, the urban expansion and therefore many different impacts in life quality happened, in spatial organization and local landscape. In this context, the present work aims to analyze the quality of life in Poços de Caldas, through quantitative indicators and the perception of its residents.
\end{abstract}

Keywords: Quality of Urban Life; Landscape; Tourism.

\footnotetext{
${ }^{1}$ Doutor em Geografia: Organização do Espaço (2014), cursados na UNESP - Campus de Rio Claro. Email: alexandre.andrade@ifsuldeminas.edu.br.

${ }^{2}$ Graduanda em Geografia (licenciatura) pelo Instituto Federal de Educação, Ciência e Tecnologia do Sul de Minas Gerais - Campus Poços de Caldas.

${ }^{3}$ Graduando em Geografia (licenciatura) pelo Instituto Federal de Educação, Ciência e Tecnologia do Sul de Minas Gerais - Campus Poços de Caldas.
} 


\section{CRECIMIENTO POBLACIONAL, PAISAJE Y CALIDAD DE VIDA EN POÇOS DE CALDAS (MG), UNA CIUDAD MEDIA TURÍSTICA}

\section{Resumen}

Poços de Caldas, es un municipio ubicado en el sur de Minas Gerais que tiene una población de 152.435 habitantes (IBGE 2010). Desde que comenzó su formación como ciudad, muestra una importancia significativa de la actividad turística, especialmente, debido a las fuentes de agua hidrotermales y su paisaje montañoso. Sin embargo, a mediados del siglo XX se inició un proceso de diversificación y desarrollo de la economía local, que favoreció el crecimiento poblacional, la expansión urbana y, en consecuencia, hubo diferentes impactos en la calidad de vida, en la organización espacial y en el paisaje local. En este contexto, el presente trabajo tiene como objetivo analizar la calidad de vida en Poços de Caldas, por médio de indicadores cuantitavos y de la percepción de quienes allí viven.

Palabras clave: Calidad de Vida Urbana; Paisajes; Turismo.

\section{INTRODUÇÃO}

O munícipio de Poços de Caldas está localizado no sul do estado de Minas Gerais, na divisa com o estado de São Paulo. Em decorrência da existência de fontes de águas hidrotermais, com propriedades medicinais, a cidade apresenta importante atividade turística desde os primórdios de sua formação, no final do século XIX. O espaço urbano, nos primeiros momentos de sua constituição, se resumia a algumas construções nas proximidades das fontes de águas hidrotermais, mas, com a implantação da ferrovia ligando a cidade a outras partes do país, a infraestrutura turística gradativamente foi se expandindo, assim como o número de visitantes.

A área central de Poços de Caldas, na primeira metade do século XX, abrigava uma diversificada infraestrutura de apoio ao turismo, como hospedarias, cassinos e restaurantes, e seu espaço público recebeu amplos investimentos na implantação de praças, parques, termas e fontes. Entretanto, a partir dos anos cinquenta do mencionado século, houve uma significativa expansão e diversificação das atividades econômicas no município, e por consequência um considerável crescimento populacional (ANDRADE, 2005; OLIVEIRA, 2014).

Com 152.435 habitantes (IBGE, 2010), o munícipio de Poços de Caldas é classificado como um "Centro Sub-Regional A” (IBGE: REGIC - Regiões de Influência das Cidades, 2007). Seu contingente populacional, atrelado a sua posição na rede urbana, fazem com que Poços de Caldas seja considerada como uma cidade média, e atraia significativo contingente de pessoas, provenientes de sua área de influência, devido as infraestruturas comerciais e de prestações de 
SOCIEDADE E

TERRITÓRIO
ANDRADE, Alexandre Carvalho de

RAMOS, Giovanna Moraes

MARTINS, Raphael Miranda

serviços de saúde, educação, entretenimento, dentre outros. E, por sua condição de centro receptor, também recebe turistas, motivados pelos atrativos locais.

As intensas mudanças que ocorreram na cidade de Poços de Caldas, decorrentes de questões demográficas, econômicas, políticas e socioculturais, incidiram em sua paisagem, em sua ocupação espacial e na qualidade de vida dos seus moradores. E, neste contexto, se algumas mudanças são positivas, outras trouxeram impactos negativos para a cidade. Tendo em vista estas situações, o presente trabalho tem como objetivo analisar a qualidade de vida dos moradores de Poços de Caldas, fazendo usos de dois recursos, a avaliação de indicadores socioeconômicos e a percepção ambiental de seus habitantes. No primeiro caso, no intuito de verificar as mudanças nos indicadores socioeconômicos no período entre 1991 e 2010 e, no segundo, com a intenção de, além de confrontar os dados quantitativos com a percepção dos moradores, conhecer as relações destes com a paisagem e com as mudanças atreladas ao crescimento populacional e as dinâmicas socioespaciais que ocorrem no município.

\section{PAISAGEM E QUALIDADE DE VIDA EM CIDADES TURÍSTICAS}

Pires (2001, p.140), elucida que "paisagem e turismo são duas realidades intimamente relacionadas, a paisagem é um elemento substancial do fenômeno turístico e, portanto, um recurso de grande valor no desenvolvimento e na consolidação da oferta turística". O turista constrói sua percepção sobre o lugar visitado na medida em que observa os aspectos de sua paisagem, as infraestruturas, os aspectos socioculturais e a qualidade de vida dos moradores.

Nas metrópoles, mas também em cidades médias, a exemplo de Poços de Caldas, as transformações que coexistem e se sucedem em seu espaço urbano, decorrentes de ações econômicas, demográficas, políticas e socioculturais, refletem diretamente em suas paisagens e na qualidade de vida de seus moradores. Para Santos (1996, p. 67):

\footnotetext{
A paisagem existe através de suas formas, criadas em momentos históricos diferentes, porém coexistindo no momento atual. No espaço, as formas de que se compõe a paisagem preenchem, no momento atual, uma função atual, como resposta às necessidades atuais da sociedade. Tais formas nasceram sob diferentes necessidades, emanaram de sociedades sucessivas, mas só as formas mais recentes correspondem a determinações da sociedade atual.
}

Por constituir um importante atributo para o desenvolvimento da atividade turística, a paisagem necessita ser agradável, tanto para os turistas quanto especialmente para o cotidiano dos moradores, contribuindo, dessa forma, para manter uma boa imagem do centro receptor. 
De acordo com Cruz (2002, p.109), “a paisagem é a primeira instância do contato do turista com o lugar visitado e por isso ela está no centro das atratividades dos lugares para o turismo", sendo assim, a adequação da paisagem deve ocorrer em todos os setores do centro receptor para transmitir uma imagem positiva do local ao turista, já que este não se interessaria em passear em um local sujo, confuso e degradado; além do mais, estes fatores são plenamente negativos para os moradores locais.

Para a atividade turística, o rápido crescimento populacional rápido e a expansão urbana desordenada e com expressivas desigualdades socioespaciais, como inclusive ocorrem em centros receptores, são bastante maléficos, pois resultam no aumento de problemas que afetam a qualidade de vida dos residentes, como a insegurança, a perda da tranquilidade, o congestionamento de veículos, a poluição visual, a descaracterização da paisagem, entre outros. As famílias de maior rendimento, assim como as empresas com mais recursos financeiros, inclusive as turísticas, são as beneficiadas pelas melhores localizações dentro de uma cidade, proporcionando para as famílias de baixa renda as piores opções, tanto em nível físico quanto social, como descreve Carlos (1994, p. 77):

As contradições emergem na paisagem urbana em toda sua plenitude, os contrastes e as desigualdades de renda afloram. $\mathrm{O}$ acesso a um pedaço de terra, o tipo e o material de construção, espelham nitidamente as diferenciações de classe.

Para haver melhorias na paisagem, condição fundamental para a consolidação das atividades turísticas, um centro receptor deve, necessariamente, diminuir as desigualdades socioespaciais e evitar a degradação de seus recursos paisagísticos, ambientais e socioculturais, pois estes fatores desmotivam a afluência dos visitantes, e reduzem as perspectivas do aumento e da democratização dos recursos provenientes do turismo, conforme mostra Serpa (2002, p. 176):

No caso do turismo, faz-se necessário um planejamento estratégico local que visualize a superação do padrão periférico de ocupação (antes de tudo um problema social!) a partir de programas de capacitação de mão de obra e geração de renda para os moradores dos destinos turísticos.

O desenvolvimento econômico de uma localidade e a boa qualidade de vida de sua população já constitui um ambiente propício para o turismo pelo fato de conferir uma sensação de ambiente aprazível e organizado ao local. Com relação a qualidade de vida urbana, Souza (2002, p. 62) assinala que, "no que tange a qualidade de vida, ela corresponde à crescente 
SOCIEDADE E

TERRITÓRIO
ANDRADE, Alexandre Carvalho de

RAMOS, Giovanna Moraes

MARTINS, Raphael Miranda

satisfação das necessidades - tanto básicas quanto não básicas, tanto materiais quanto imateriais - de uma parcela cada vez maior da população".

Güell (1997, p.163) descreve que para o estudo da qualidade de vida dos moradores de uma localidade, deve se levar em conta, além dos dados quantitativos, a percepção dos moradores da área em questão. Assim, de acordo com Bravo e Vera (1993, p.277):

\footnotetext{
A evolução do conceito de qualidade de vida permite assinalar três momentos em relação aos critérios adotados e desenvolvidos em diferentes trabalhos: a) os estudos com indicadores do tipo objetivo, com dados de fontes estatísticas, de caráter quantitativo; b) os estudos com indicadores subjetivos, da percepção do homem sobre suas necessidades, de caráter qualitativo; c) a combinação de ambos os critérios com a incorporação da dimensão espacial.
}

Desta forma, a necessidade de se analisar a qualidade de vida a partir da interação entre dados quantitativos e qualitativos, como foi realizado neste trabalho, se deu por tornar a pesquisa mais representativa da realidade de um local, já que, em diversas situações, o que pode ser considerado como essencial para a boa qualidade de vida de uma população pode não ser considerado por outro grupo humano.

\section{PROCEDIMENTOS METODOLÓGICOS}

Para a realização deste trabalho, alguns procedimentos metodológicos foram utilizados, de maneira integrada. Inicialmente, foram realizadas as revisões bibliográficas sobre questões teóricas que embasaram a pesquisa, e o levantamento de informações referentes ao município de Poços de Caldas. Também houve diversos trabalhos de campo, com o intuito de avaliar aspectos como o uso e a ocupação do espaço, a paisagem, as desigualdades socioespaciais, as atividades turísticas, e as condições socioambientais locais. Além destes, para se mensurar a qualidade de vida dos moradores de Poços de Caldas foram realizadas as análises quantitativas, por meio de indicadores demográficos e socioeconômicos, e as análises qualitativas, por intermédio da aplicação e interpretação de questionários com habitantes do município.

Gerardi e Silva (1981) citam que as técnicas quantitativas possibilitam maior objetividade e precisão nas análises, contribuindo para se conhecer a realidade de um local, região ou país, assim como para comparar unidades espaciais distintas e para traçar uma evolução histórica do atributo escolhido. No contexto deste trabalho, os indicadores demográficos, obtidos nos Censos Demográficos (IBGE), permitiram evidenciar o processo de crescimento populacional que ocorreu em Poços de Caldas. Por sua vez, indicadores 
socioeconômicos, relacionados a renda, escolaridade, saúde e saneamento, disponíveis no Atlas do Desenvolvimento Humano no Brasil (2013), possibilitaram avaliar a qualidade de vida dos moradores do município, tendo como períodos os anos de 1991, 2000 e 2010.

Conhecer a opinião dos moradores, sobre as transformações em sua localidade, permite realizar o planejamento e a gestão de uma área com maior eficiência e com melhores resultados, já que são avaliados os interesses e necessidades do usuário direto (OLIVEIRA, 1999). Com a finalidade de verificar a percepção dos moradores de Poços de Caldas, com relação às mudanças ocorridas em seu espaço vivido, foi necessária a aplicação e interpretação de questionários com os habitantes da área de estudo. Este instrumento de medida colaborou para averiguar os impactos destas alterações para a paisagem e para a qualidade de vida dos moradores.

Os questionários foram aplicados durante trabalhos de campo, em outubro de 2017, na região central de Poços de Caldas, local este com circulação de moradores dos mais diversos bairros do município e, consequentemente, de condições socioeconômicas distintas. Constituíram os sujeitos da pesquisa cinquenta pessoas, sendo que dois critérios foram estipulados: residir em Poços de Caldas e ter idade igual ou maior a 16 anos.

O questionário foi estruturado em duas partes, sendo a primeira apenas referente ao perfil do sujeito da pesquisa: idade, gênero, estado civil, escolaridade, tempo de moradia no município e ocupação profissional. A segunda parte, constituída por perguntas abertas e fechadas, teve a finalidade de conhecer a relação existente entre os moradores de Poços de Caldas e seu espaço vivido, e as mudanças que ocorreram, ocorrem, e podem vir a ocorrer, na paisagem e na qualidade de vida dos habitantes da área de estudo.

\section{CRESCIMENTO POPULACIONAL E INDICADORES DE QUALIDADE DE VIDA EM POÇOS DE CALDAS}

Poços de Caldas apresenta importante função turística desde o final do século XIX, devido as suas águas hidrotermais e suas condições paisagísticas. Entretanto, a partir da década de 50 do século $\mathrm{XX}$, ocorreu um processo de diversificação econômica do município, especialmente pela extração de recursos minerais, pela industrialização e pela expansão das atividades comerciais e de prestação de serviços. Como reflexo deste processo de desenvolvimento econômico, a população de Poços de Caldas passou de 25.237 em 1950, para 88.354 em 1980, atingindo 154.492 no ano de 2010, sendo destes $97 \%$ residentes na área urbana (IBGE: Censos Demográficos). 
SOCIEDADE E

TERRITÓRIO
ANDRADE, Alexandre Carvalho de

RAMOS, Giovanna Moraes

MARTINS, Raphael Miranda

O município de Poços de Caldas, no período entre 1991 e 2010, apresentou considerável crescimento em seu IDH (Índice de Desenvolvimento Humano), que passou de 0,581 em 1991, para 0,716 em 2000 e 0,779 em 2010 (Atlas do Desenvolvimento Humano no Brasil, 2013). Isto foi consequência das melhorias nas condições de renda, educação e longevidade, índices estes utilizados para calcular o IDH (tabela 1).

Tabela 1: IDH e seus componentes, no município de Poços de Caldas, nos anos de 1991, 2000 e 2010.

\begin{tabular}{|lrrr|}
\hline $\begin{array}{l}\text { Indice de Desenvolvimento Humano Municipal e seus componentes - Município - Poços de Caldas - MG } \\
\text { IDHM e componentes }\end{array}$ & $\mathbf{1 9 9 1}$ & $\mathbf{2 0 0 0}$ & $\mathbf{2 0 1 0}$ \\
\hline IDHM Educação & 0,367 & 0,574 & 0,706 \\
$\quad \%$ de 18 anos ou mais com fundamental completo & 32,36 & 45,72 & 61,25 \\
\hline $\begin{array}{l}\text { \% de } 5 \text { a } 6 \text { anos na escola } \\
\text { \% de 11 a 13 anos nos anos finais do fundamental REGULAR SERIADO ou com fundamental }\end{array}$ & 53,67 & 84,81 & 97,34 \\
\hline $\begin{array}{l}\text { completo } \\
\quad \text { de 15 a 17 anos com fundamental completo }\end{array}$ & 55,42 & 77,94 & 88,05 \\
\hline \% de 18 a 20 anos com médio completo & 31,38 & 57,79 & 65,23 \\
\hline IDHM Longevidade & 15,84 & 36,53 & 52,21 \\
\hline$\quad$ Esperança de vida ao nascer & 0,775 & 0,850 & 0,872 \\
\hline IDHM Renda & 71,48 & 75,98 & 77,31 \\
\hline$\quad$ Renda per capita & 0,689 & 0,753 & 0,768 \\
\hline Fonte: PNUD, Ipea e FJP & 580,65 & 867,68 & 953,96 \\
\hline
\end{tabular}

Fonte: Atlas do Desenvolvimento Humano no Brasil, 2013

O indicador "IDHM Educação" do município de Poços de Caldas, começou baixo em 1991, tendo índice de 0,367, mas houve uma significativa melhoria em 2000, passando a 0,574. Percebe-se que em 2010 este índice apresentou crescimento no município, alcançando a marca de 0,706 . Sobre a educação, conclui-se que houve avanços evidentes, que são refletidos pelas maiores taxas de frequência escolar e na conclusão de ciclos escolares (fundamental, médio e superior). O índice de moradores de Poços de Caldas que possuía curso superior passou de 7,7\% em 1991, para 14,0\% em 2010 (Atlas do Desenvolvimento Humano no Brasil, 2013). Importante mencionar que nas últimas duas décadas foram implantadas, em Poços de Caldas, instituições públicas de ensino técnico (IFSULDEMINAS) e superior (UNIFAL, IFSULDEMINAS e UEMG), e neste último caso também privadas (PUC/MG, Unifenas e Pitágoras), que atraem estudantes do município, mas também de outras localidades.

Com relação ao "IDHM Saúde", representado pela esperança de vida ao nascer (Longevidade), Poços de Caldas apresentou uma expressiva melhora, no período entre 1991 e 
2010, pois passou de 71,48 para 77,31 anos. Isto é resultado de fatores como a redução da mortalidade infantil (20,7 mortes para cada nascidos vivos em 1991 e 11,27 em 2010 - Atlas do Desenvolvimento Humano no Brasil, 2013), de melhorias das condições de saúde (hospitais, policlínicas) no município, e de aspectos socioambientais (saneamento básico, coleta de lixo...).

O indicador "IDHM Renda" é representado pela renda per capita, que constitui um índice socioeconômico que permite avaliar o grau de desenvolvimento de determinada localidade. No caso de Poços de Caldas, o aumento foi constante no período analisado (1991 2010), pois passou de $\mathrm{R} \$ 580,65$ em 1991, para $\mathrm{R} \$ 867,68$ em 2000 e $\mathrm{R} \$$ 953,96 em 2010, índices estes superiores a média brasileira nos mesmos anos $(\mathrm{R} \$ 447,56, \mathrm{R} \$ 592,46$ e $\mathrm{R} \$ 793,87$, respectivamente). Outro fator positivo foi a pequena redução nas desigualdades sociais no município (0,52 em 1991 e 0,50 em 2010), atestada pelo Coeficiente de Gini (Atlas do Desenvolvimento Humano no Brasil, 2013).

O aumento da renda per capita, e a redução na concentração de renda, aliados a fatores como as maiores oportunidades no mercado de trabalho local, a melhoria das condições de educação, assim como os projetos governamentais para redução da pobreza, como o Bolsa Família, favoreceram a redução dos percentuais da população abaixo das linhas da pobreza (12,67\% em 1991 e 2,93\% em 2010 residiam em moradias com menos de 1⁄2 salário mínimo per capita) e da miséria (2,63\% em 1991 e 0,32 em 2010 residiam em moradias com menos de 1/4 salário mínimo per capita) no município de Poços de Caldas (Atlas do Desenvolvimento Humano no Brasil, 2013).

Apesar das melhorias nos indicadores de renda, é fundamental mencionar que, refletindo sua situação de cidade capitalista, as condições socioeconômicas dos moradores e dos investidores colaboram para definir as produções econômicas e socioespaciais e, por consequência, as áreas em que cada grupo se apropria no espaço urbano de Poços de Caldas. Neste contexto, os de maior poder aquisitivo são beneficiados com mais possibilidades de escolhas, restando aos habitantes mais pobres as áreas mais distantes e/ou mais precárias das cidades (CARLOS, 2007; SOUZA, 2011). A figura 1 demonstra as desigualdades socioespaciais em Poços de Caldas. 
SOCIEDADE E

TERRITÓRIO
ANDRADE, Alexandre Carvalho de

RAMOS, Giovanna Moraes

MARTINS, Raphael Miranda

Figura 1: Mapa dos rendimentos das pessoas com 10 anos ou mais, na cidade de Poços de Caldas, no ano de 2010.

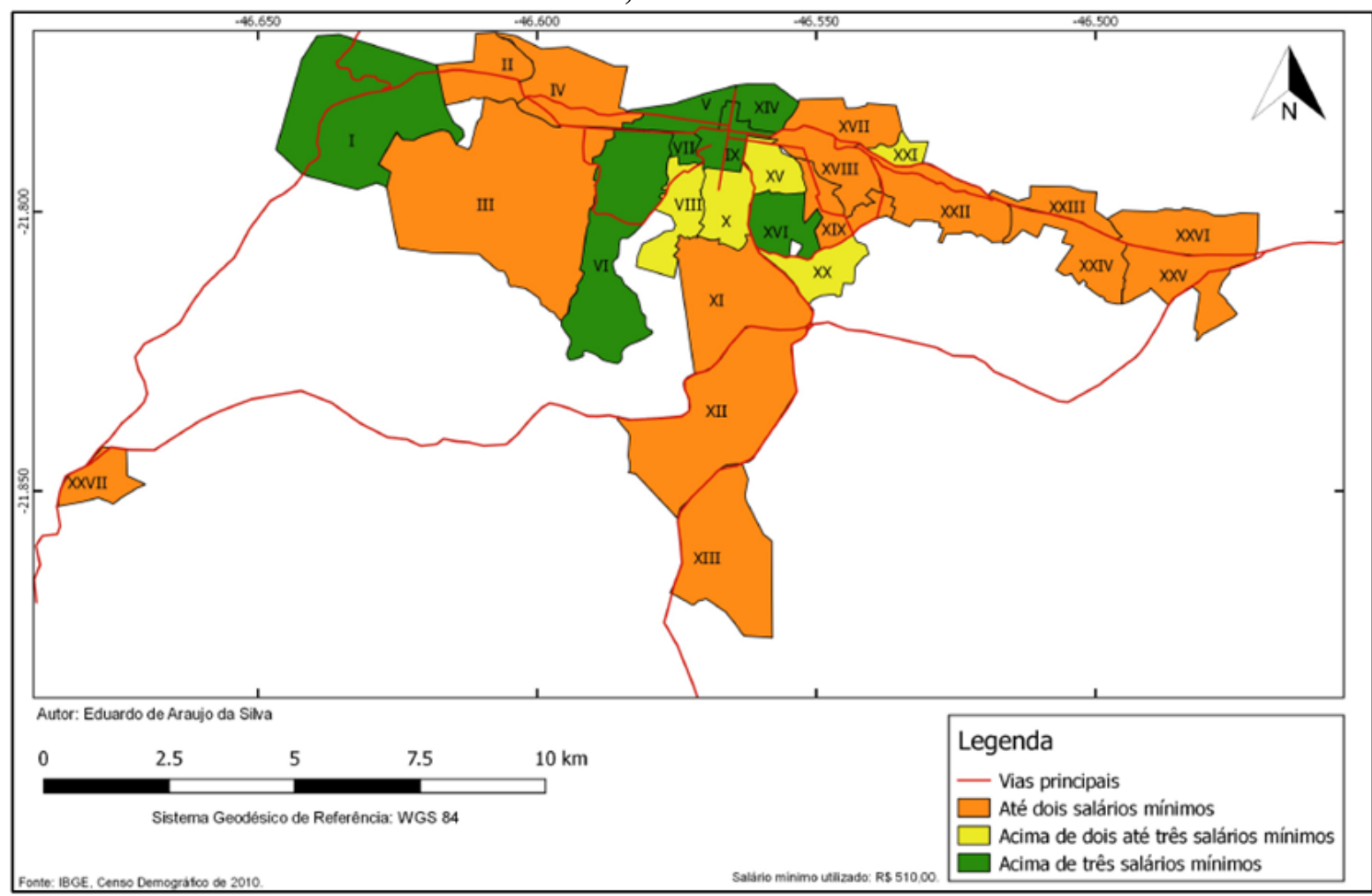

Fonte: SILVA, 2018.

Os setores da cidade em que predominam os habitantes com altos rendimentos estão na área central (V, VII e IX), pericentrais (XIV e XVI) e em algumas áreas da zona oeste (I e VI), sendo esta última considerada uma área de expansão urbana de maior valorização socioeconômica, e que abriga estabelecimentos comerciais e de prestação de serviços que atraem moradores de Poços de Caldas e de sua área de influência, tais como shopping-center, lojas de mobiliários e concessionárias de veículos, campus universitários (PUC/MG, Pitágoras, UEMG e UNIFAL), hospitais, dentre outros, e também os condomínios fechados existentes no município. As áreas com rendimentos intermediários, em sua maioria estão na região pericentral, e se anteriormente eram consideradas como periféricas e de baixa renda, atualmente recebem relevantes empreendimentos imobiliários, em sua maioria por meio da verticalização. Por sua vez, as áreas ocupadas por moradores de menores rendimentos estão, em sua maior parte, na zona sul, onde predominam conjuntos habitacionais e loteamentos populares, e a zona leste, com bairros ocupando locais com significativa declividade (OLIVEIRA, 2014; SILVA, 2018). 
Apesar de haver significativas desigualdades socioespaciais na cidade de Poços de Caldas, de acordo com o Atlas do Desenvolvimento Humano no Brasil (2013), entre os anos de 1991 e de 2010 houve melhorias nas condições de moradias, conforme podem ser verificadas pelos percentuais de moradores que vivem em domicílios com água encanada e banheiro (95,28\% em 1991 e 98,57\% em 2010), com coleta de lixo (96,2\% em 1991 e 99,89\% em 2010) e com energia elétrica $(99,49 \%$ em 1991 e 99,92\% em 2010).

As satisfatórias condições de qualidade de vida no município já foram evidenciadas por Andrade (2005). Nesta pesquisa, quando comparado a setenta e sete cidades médias (população entre 50 e 200 mil habitantes, pelo critério do autor), com notória importância da função turística, o município de Poços de Caldas proporcionou indicadores melhores do que a média das "cidades médias turísticas" em todos os dezoito atributos, que foram agrupados quanto aos rendimentos, o acesso aos bens de consumo, a abrangência dos serviços públicos, a escolaridade e a saúde.

Nas últimas décadas o município de Poços de Caldas apresentou consideráveis transformações demográficas, econômicas e ambientais que refletiram diretamente na ocupação do espaço urbano municipal e nas condições de vida de seus moradores. Se por um lado houve um processo de desenvolvimento econômico e social, conforme evidenciado nos indicadores quantitativos demonstrados, por outro é nítido o surgimento e agravamento de consideráveis impactos nas condições socioambientais e paisagísticas municipais.

\section{A PERCEPÇÃO DOS MORADORES DE POÇOS DE CALDAS}

A primeira parte do questionário consiste em dados sobre os participantes da pesquisa. Dentre os sujeitos da pesquisa vinte e dois (44\%) possuem entre 16 e 25 anos, quatorze (28\%) entre 26 e 35 anos, cinco (10\%) entre 36 e 45, e nove (18\%) acima de 46 anos. Com relação ao gênero, vinte e sete (54\%) são do sexo feminino, e vinte e três (46\%) são do sexo masculino.

$\mathrm{O}$ estado civil dos sujeitos da pesquisa se distribui da seguinte maneira: trinta e três (66\%) são solteiros, onze 22(\%) são casados, seis (12\%) são divorciados, não havendo viúvos.

Com relação a naturalidade dos sujeitos da pesquisa, vinte e seis (52\%) são naturais de Poços de Caldas, doze (24\%) são naturais de outros municípios do sul de Minas Gerais, dois (4\%) de outras regiões de Minas Gerais, e dez (20\%) de outros estados, sendo cinco de São Paulo e os demais da Bahia, Ceará, Distrito Federal, Paraná e Rio de Janeiro. No que se refere ao tempo de residência no município, trinta e três (66\%) residem em Poços de Caldas a 16 anos ou mais, seis (12\%) entres 6 e 15 anos, e onze (22\%) a 5 anos ou menos. 
SOCIEDADE E

TERRITÓRIO
ANDRADE, Alexandre Carvalho de

RAMOS, Giovanna Moraes

MARTINS, Raphael Miranda

Quanto a escolaridade dos sujeitos da pesquisa, cinco (10\%) possuem até o ensino fundamental incompleto, um (2\%) possui o fundamental completo, doze (24\%) possuem o ensino médio incompleto, dezoito (36\%) possuem o médio completo. Oito (16\%) dos participantes da pesquisa possuem ensino superior incompleto, e seis (12\%) possuem superior completo.

A respeito da ocupação profissional, obteve-se as seguintes respostas: quatorze (28\%) estão no setor de serviços, nove (18\%) estão no setor comercial, dois (4\%) estão no setor industrial e dois (4\%) são autônomos. Onze (22\%) são estudantes e dois (4\%) são aposentados. Sete (14 \%) estão fora do mercado de trabalho, sendo três desempregados, dois "do lar" e dois declararam "não fazer nada". Três (6\%) não especificaram.

A segunda parte do questionário consiste em sete perguntas, abertas e fechadas, referentes as opiniões dos moradores acerca da qualidade de vida em Poços de Caldas, assim como de aspectos referentes a paisagem e ao ambiente local. A primeira pergunta objetivou saber o que os sujeitos da pesquisa consideram fundamentais para se ter uma boa qualidade de vida (tabela 2).

\section{Tabela 2: O que você considera fundamental para uma população ter qualidade de} vida? ( $\mathbf{N = 5 0 )}$

\begin{tabular}{lc}
\hline Respostas & Número \\
\hline Saúde & 21 \\
Educação & 14 \\
Desenvolvimento econômico, emprego e renda & 11 \\
Justiça e/ou Politica & 9 \\
Organização e conservação do espaço urbano & 8 \\
Infraestrutura de serviços públicos & 8 \\
Meio Ambiente & 4 \\
Segurança Pública & 4 \\
Lazer e Cultura & 2 \\
Outros & 8 \\
\hline Total & 89 \\
\hline Fonte: Pesquisas de campo
\end{tabular}

Pode-se observar que das oitenta e nove respostas, vinte e uma $(23,6 \%)$ colocaram saúde como elemento fundamental para a qualidade de vida de uma determinada população. De acordo com Pereira, Teixeira e Santos (2012), qualidade de vida muitas vezes acaba sendo associada como saúde, e dependendo da área de estudo a palavra também é utilizada com o 
mesmo sentido. Isso explicaria o motivo de significativo número de respostas trazer "saúde" como algo necessário para uma boa qualidade de vida.

O segundo item mais mencionado pelos sujeitos da pesquisa foi a educação, sendo apontada em quatorze $(15,6 \%)$ das respostas, seguido de elementos referentes a desenvolvimento econômico, emprego e renda, que totalizaram onze $(12,4 \%)$.

Os três itens mais mencionados totalizam mais da metade das respostas, sendo citados quarenta e seis vezes $(51,6 \%)$. Interessante mencionar que estes três elementos, de forma geral, são utilizados como critérios para o Índice de Desenvolvimento Humano (IDH), em que os indicadores de qualidade de vida dos moradores de Poços de Caldas apresentaram expressivas melhoras entre 1991 e 2010.

As respostas restantes estão ligadas a temas variados que compõe a qualidade de vida de uma população, tais como justiça e/ou política, organização e conservação do espaço urbano, infraestrutura de serviços públicos, meio ambiente, segurança pública, lazer e cultura, e outros.

A segunda pergunta objetivou saber como os sujeitos da pesquisa avaliam a qualidade de vida dos moradores de Poços de Caldas (tabela 3).

\section{Tabela 3: Como você avalia a qualidade de vida dos moradores de Poços de Caldas $(\mathrm{N}=50)$.}

\begin{tabular}{lc}
\hline Respostas & Número \\
\hline Ótima & 5 \\
Boa & 28 \\
Regular & 14 \\
Ruim & 2 \\
Péssima & 1 \\
\hline Total & 50 \\
\hline Fonte: Pesquisas de campo &
\end{tabular}

Como se percebe na tabela, 28 das pessoas (56\%) consideram a qualidade de vida dos moradores de Poços de Caldas como boa, contra 17 (34\%) que consideram a qualidade de vida como regular ou inferior (ruim ou péssima). Os 10\% restantes acreditam que a qualidade de vida é ótima, mostrando certo otimismo em relação ao assunto, já que este valor é superior aos valores das respostas "ruim" e "péssima" somados (4 e $2 \%$ respectivamente). Como as avaliações positivas da cidade foram bem superiores as negativas (66\% ótima e boa contra $6 \%$ ruim e péssima), é possível constatar que no geral as pessoas estão satisfeitas com sua qualidade de vida em Poços de Caldas, algo que condiz com os indicadores socioeconômicos anteriormente demonstrados neste trabalho. 
SOCIEDADE E

TERRITÓRIO
ANDRADE, Alexandre Carvalho de

RAMOS, Giovanna Moraes

MARTINS, Raphael Miranda

Os aspectos do município de Poços de Caldas, que mais agradam aos sujeitos da pesquisa, são demonstrados na tabela 4 .

Tabela 4: Que aspectos mais lhe agradam em Poços de Caldas? (N=50

\begin{tabular}{lc}
\hline Respostas & Número \\
\hline Pontos turísticos & 16 \\
Cidade como um todo & 11 \\
Calma, tranquilidade e segurança & 8 \\
Clima & 8 \\
Paisagem & 7 \\
Meio Ambiente e áreas verdes & 6 \\
Cultura e Lazer & 3 \\
Nada & 2 \\
Outros & 7 \\
\hline Total & 60 \\
\hline
\end{tabular}

Fonte: Pesquisas de campo

Significativa parcela dos sujeitos da pesquisa (16, pessoas, $26,7 \%$ do total) mencionou que os pontos turísticos são os aspectos que mais agradam na cidade. "A cidade como um todo" foi a segunda mais citada, com onze menções (18,3\%). "Calma, tranquilidade e segurança” e "clima" foram mencionadas oito vezes cada (13,3\%). "Paisagem" e "meio ambiente e áreas verdes" tiveram somadas treze respostas $(21,7 \%)$. Apenas duas das cinquenta pessoas responderam que nada agrada em Poços de Caldas.

No transcorrer do século XX, progressivamente a qualidade visual da paisagem passou a ser considerada uma variável importante nas intervenções que são realizadas em um local, em especial porque a sociedade começou a valorizar sua contribuição para a qualidade de vida (ESPINO, 1999). Importante associar os aspectos relacionados às paisagens naturais e construídas (pontos turísticos, paisagem, áreas verdes, cidade...), mencionados pelos sujeitos da pesquisa, com os benefícios que oferecem, também, aos turistas que visitam Poços de Caldas. A paisagem municipal apresenta importante valor turístico, com a presença de montanhas, com destaque para a Serra de São Domingos, e na área central da cidade há vias largas, praças e parques, museu, espaços culturais, e edificações com significativa beleza arquitetônica.

De acordo com Lynch (1960, p.58), "as pessoas observam a cidade à medida que nela se deslocam e os outros elementos organizam-se e relacionam-se ao longo destas vias". A percepção de estar em uma cidade onde a qualidade de vida da população é satisfatória, que transmite calma, tranquilidade e segurança, e que as paisagens são agradáveis, é um aspecto 
essencial para a satisfação dos seus moradores, mas tendo em vista que Poços de Caldas é uma cidade com importante função turística, isto também colabora para a satisfação dos turistas que a visita, algo que acaba sendo favorável para a economia local. Assim, a organização espacial e a conservação dos recursos naturais e construídos devem necessariamente serem efetivadas, seja uma cidade turística ou não (YÁZIGI, 2003).

Os aspectos do município de Poços de Caldas, que mais desagradam aos sujeitos da pesquisa, são demonstrados na tabela 5 .

Tabela 5: Que aspectos mais lhe desagradam em Poços de Caldas? (N=50)

\begin{tabular}{lc}
\hline Respostas & Número \\
\hline Mercado de trabalho & 9 \\
Mobilidade/Trânsito & 6 \\
Alto custo de vida & 6 \\
Infraestrutura deficiente & 6 \\
Condições do Meio físico & 5 \\
Insegurança & 5 \\
Nada desagrada & 4 \\
Relações Interpessoais & 4 \\
Moradores de Rua/ Pedintes & 3 \\
Saneamento/Poluição & 3 \\
Descuido das pessoas com a cidade & 2 \\
Não sei & 1 \\
Outros & 2 \\
\hline Total & 56 \\
\hline
\end{tabular}

Fonte: Pesquisas de campo

O aspecto que mais desagrada foi o "mercado de trabalho", com nove menções $(16,1 \%$ do total). Um exemplo de resposta sobre a falta de emprego foi de um sujeito da pesquisa, do sexo feminino, de trinta e cinco anos, que está atualmente trabalhando, mas admite a carência de emprego ao mencionar que "falta emprego, faltam indústrias no município de Poços de Caldas".

Empatados em segundo lugar, como os aspectos mais citados, foram mobilidade/trânsito, alto custo de vida, e infraestrutura deficiente, cada um sendo mencionado seis vezes $(10.7 \%)$, totalizando dezoito respostas contendo esses temas. Em número menor, mas também relevantes foram as menções a fatores como as condições do meio físico (relevo montanhoso que dificulta a mobilidade urbana, por exemplo), insegurança, presença de moradores de rua/pedintes, saneamento/poluição, descuido das pessoas com a cidade e outros.

Se percebe, pelas respostas dos sujeitos da pesquisa, que vários fatores desagradam no município, e em boa parte estrão atrelados a questões possíveis de serem melhoradas, por meio 
SOCIEDADE E

TERRITÓRIO
ANDRADE, Alexandre Carvalho de

RAMOS, Giovanna Moraes

MARTINS, Raphael Miranda

de ações dos governantes, como servem de exemplos a mobilidade/trânsito, a infraestrutura deficiente e o saneamento. O desenvolvimento econômico de uma localidade e a boa qualidade de vida de sua população são aspectos plenamente favoráveis ao turismo, pelo fato de conferir uma sensação de ambiente aprazível e organizado a um lugar, o que desperta o interesse das pessoas em conhecê-lo (YÁZIGI, 2003). Assim, de acordo com Souza (2002, p.61):

Pode-se dizer que está diante de um autêntico processo de desenvolvimento socioeconômico quando se constata uma melhoria da qualidade de vida e um aumento da justiça social. A mudança social positiva, no caso, precisa contemplar não apenas as relações sociais, mas, igualmente, a espacialidade.

Bravo (1997) salientou que o planejamento do desenvolvimento urbano é de suma importância para melhorar a qualidade de vida nas cidades, por orientar a ocupação espacial em harmonia com as condições ambientais e para o benefício de seus moradores. Pujadas e Font (1999) citaram que o planejamento urbano originou-se da necessidade de ordenar o espaço em cidades com rápido crescimento populacional, em que cada parcela do solo urbano possui diversos usos possíveis, seja com finalidades residenciais, econômicas, administrativas, recreacionais ou de contatos sociais. Para os autores, a análise do espaço e de sua dinâmica, contrastada com o modelo de cidade que se quer atingir, pode proporcionar os critérios para decidir qual é o uso mais adequado nos mais diversos setores do espaço urbano e municipal.

É plenamente recomendável haver interesse dos governantes em minimizar os aspectos que foram considerados pelos sujeitos da pesquisa como desagradáveis do município de Poços de Caldas, pois, além de prejudicar efetivamente a qualidade de vida da população local, em especial a de menores rendimentos e residentes nos bairros com pior infraestrutura, podem vir a prejudicar a sua atratividade junto aos visitantes. Apesar disso, conforme se verificou em trabalhos de campo, na mídia, e na análise dos documentos oficiais, tais como o plano diretor e o zoneamento urbano, as ações que almejam o planejamento e a gestão do espaço urbano de Poços de Caldas se mostram bastante deficitárias, e problemas como mobilidade/trânsito, insegurança e falta de infraestrutura são cada vez mais recorrentes e graves no cotidiano local.

Na tabela 6 são demonstradas as percepções dos sujeitos da pesquisa quanto as relações entre o crescimento populacional e as mudanças que ocorrem na cidade de Poços de Caldas. 
Tabela 6: Você considera que o aumento da população que ocorre em Poços de Caldas, modifica a cidade em qual intensidade? $(\mathrm{N}=50)$

\begin{tabular}{lc}
\hline Respostas & Número \\
\hline Extremamente alta & 8 \\
Alta & 19 \\
Média & 18 \\
Pouca & 4 \\
Nada & 1 \\
\hline Total & 50 \\
\hline Fonte: Pesquisas de campo &
\end{tabular}

45, dentre os 50 sujeitos da pesquisa (90\% do total), consideram, em intensidades média, alta ou extremamente alta, que o aumento da população está associado às modificações que ocorrem na cidade, O restante (10\%) disse que este aumento não influencia muito, sendo que $8 \%$ afirmaram que a modificação é pouca e $2 \%$ que não modifica nada a cidade. A tabela sete elucida como as modificações advindas do crescimento populacional afetam a qualidade de vida dos moradores do município, de acordo com os sujeitos da pesquisa.

Tabela 7: De que forma você considera que o aumento da população que ocorre em Poços de Caldas modifica a qualidade de vida dos moradores? $(\mathrm{N}=38)$

\begin{tabular}{lc}
\hline Respostas & Número \\
\hline Aumento da concorrência por empregos & 10 \\
Sobrecarga da infraestrutura de serviços públicos & 10 \\
Aumento do Trânsito & 10 \\
Crescimento da violência/Insegurança & 5 \\
Ineficiência do governo & 5 \\
Custo de vida elevado & 3 \\
Expansão das oportunidades e empreendimentos & 3 \\
Crescente poluição & 3 \\
Aumento dos moradores de rua & 2 \\
Outras & 4 \\
\hline Total & 55 \\
\hline Fonte: Pesquisas de campo
\end{tabular}

Fonte: Pesquisas de campo

Dos cinquenta participantes da pesquisa, doze (24\%) assinalaram que as modificações não afetam a qualidade de vida dos habitantes do município. Os demais trinta e oito acreditam que estas mudanças afetam a qualidade de vida dos moradores, e durante as respostas foram apontadas cinquenta e cinco modificações. 
SOCIEDADE E

TERRITÓRIO
ANDRADE, Alexandre Carvalho de

RAMOS, Giovanna Moraes

MARTINS, Raphael Miranda

A maior concorrência por empregos, a sobrecarga da infraestrutura de serviços públicos, e o aumento do trânsito foram citadas dez vezes cada uma (a soma destas corresponde a 54,5\% do total). As opiniões dos seguintes sujeitos da pesquisa elucidam estas situações:

\footnotetext{
"Nem sempre a população tem acesso a boa habitação, saneamento e transportes. Há um crescimento desordenado da cidade". (Moradora de 63 anos, residindo há três anos no município).

"Serviços públicos têm de acompanhar o crescimento da cidade, o que infelizmente não ocorre”. (Morador de 29 anos, residindo há cinco anos no município).

"Falta de emprego, aumento de viventes de rua. Pessoas vêm para a cidade, sem ter onde morar, e em diversos casos ficam 'jogadas' na rua”. (Morador de 29 anos, residindo há dez anos no município).
}

A maioria das respostas aborda mudanças negativas na cidade, e além das já citadas, foram obtidas opiniões abrangendo aspectos como crescimento da violência/insegurança, ineficiência do governo, custo de vida elevado, expansão das oportunidades e empreendimentos, crescente poluição, aumento dos moradores de rua, dentre outras. O único tema mostrando que essas modificações são positivas para os moradores foi a expansão das oportunidades e empreendimentos, citado apenas três vezes.

Se observados os quatro aspectos mais mencionados na tabela 5, referente aos fatores que mais desagradam os moradores em Poços de Caldas, estão as três mudanças mais comentadas pelos participantes como consequência do crescimento populacional, tais como a maior concorrência por empregos, a sobrecarga da infraestrutura de serviços públicos, e o aumento do trânsito. Isto demonstra uma correlação, na avaliação dos sujeitos da pesquisa, entre o crescimento populacional e o aparecimento e o agravamento dos aspectos que os desagradam na cidade.

A redução de desigualdades socioespaciais, atrelada a percepção dos sujeitos da pesquisa acerca da necessidade de maior desenvolvimento econômico e de oportunidades de emprego, e a necessidade de melhor planejamento urbano, são alguns dos fatores mencionados como fundamentais para se viver com melhor qualidade de vida em Poços de Caldas (tabela 8). 
Tabela 8: O que você acha que deveria ter em Poços de Caldas para você morar com melhor qualidade de vida? $(\mathrm{N}=50)$

\begin{tabular}{lc}
\hline Respostas & Número \\
\hline Emprego e renda & 17 \\
Economia municipal & 7 \\
Melhor urbanismo & 7 \\
Melhor distribuição de renda e menor custo de vida & 6 \\
Educação & 6 \\
Saúde & 6 \\
Transporte/Mobilidade & 6 \\
Entretenimento/Cultura & 6 \\
Segurança & 5 \\
Melhora de serviços públicos & 2 \\
Está tudo bem & 2 \\
Outras & 4 \\
\hline Total & 74 \\
\hline Fonte: Pesquisas de campo &
\end{tabular}

O tema mais apontado entre os entrevistados, sobre o que poderia melhorar em Poços de Caldas, foi "emprego e renda", mencionado dezessete vezes de um total de setenta e nove $(21,4 \%)$. Além deste foram citados por sete pessoas $(8,9 \%)$ a "economia local”. As opiniões dos seguintes sujeitos da pesquisa demonstram estas situações relacionadas às questões econômicas:

\footnotetext{
"Necessita de salário melhor e menos impostos, e preços melhores, pois acham que somos todos turistas" (Moradora, 52 anos, residindo há 50 anos no município).

"Para os idosos está ótimo, mas para os jovens faltam empregos e faculdades". (Moradora, 67 anos, natural do município).
}

Também foram expressivas as menções às necessidades de melhorias das condições de saúde e educação, pois, mesmo estes índices tendo melhorado nas últimas décadas, são frequentes as reportagens na mídia local a respeito de problemas que ocorrem nas escolas e nas Unidades de Pronto Atendimento, em especial as mantidas pelo poder público. Os outros temas elencados abordam questões referentes ao urbanismo, a redução das desigualdades socioespaciais, a melhoria da infraestrutura de serviços públicos, as maiores ofertas de entretenimento e cultura, e a melhoria da mobilidade urbana, que foram assim citados pelos sujeitos da pesquisa:

“Em bairros 'populares' ter mais áreas de lazer, mais áreas verdes, uma urbanização de melhor qualidade” (Morador, 45 anos, residindo há 4 anos no município). 
SOCIEDADE E

TERRITÓRIO
ANDRADE, Alexandre Carvalho de

RAMOS, Giovanna Moraes

MARTINS, Raphael Miranda

"Igualdade ser maior. Há muito foco no centro e falta nos outros bairros. São necessárias limpeza, educação e cuidado maior com a cidade" (Morador, 27 anos, residindo há 4 anos e meio no município).

“Aspectos culturais e acesso a produtos e serviços que ainda não são encontrados em Poços de Caldas" (Morador, 18 anos, há 4 anos no município).

O processo de crescimento populacional de uma cidade, ocorre concomitante aos processos de expansão urbana e de verticalização e adensamento de construções (SPOSITO, 2008). E, no contexto de Poços de Caldas, a expansão urbana ocorreu, em diversos casos, nas áreas de significativa declividade, em especial na zona leste e na região pericentral, e/ou nas áreas com expressiva distância em relação ao centro da cidade, principalmente na zona sul, onde predominam os conjuntos habitacionais e os loteamentos populares. Por sua vez, a área central, onde historicamente o turismo se desenvolveu, além de receber maiores investimentos do poder público na manutenção de suas condições paisagísticas, é onde está concentrada a maior parte das infraestruturas de comércio e de prestação de serviços, inclusive ligadas ao turismo.

As desigualdades socioespaciais existentes em Poços de Caldas também refletem situações que ocorrem em diversas cidades médias e metrópoles brasileiras. No caso, as diferenças de renda associadas às diferenças nas estruturas de saúde, transporte, segurança e educação, que atendem aos brasileiros de acordo com as classes sociais a que pertencem, e resultam em contrastes que afetam efetivamente no viver cotidiano dos espaços urbanos. Também é importante mencionar que, no período de desenvolvimento desta pesquisa, o Brasil passa por uma grave crise econômica, que reflete nos altos índices de desemprego, e que também incide em Poços de Caldas.

\section{CONSIDERAÇÕES FINAIS}

A maioria dos sujeitos da pesquisa avaliou a qualidade de vida em Poços de Caldas como boa, regular ou ótima, e poucos acreditam que é ruim ou péssima. Tal situação apresenta relações com os indicadores socioeconômicos municipais, conforme mostrado neste trabalho, e mesmo com as condições paisagísticas e ambientais locais. Importante mencionar que, em pesquisa de Andrade (2005), se constatou, também, que a percepção dos moradores do município, a respeito da qualidade de vida em seu espaço vivido, foi significativamente favorável, com a maior parte dos entrevistados tendo a descrita como boa e/ou muito boa, sendo 
baixo o percentual que descreveu ser ruim e/ou muito ruim a qualidade de vida em Poços de Caldas. Porém, é interessante ressaltar que a quase totalidade dos moradores entrevistados admitiu, em ambas as pesquisas, que o crescimento populacional afetou a qualidade de vida, especialmente devido a perda da tranquilidade e da segurança, a dificuldade de obtenção de empregos e a sobrecarga na infraestrutura municipal.

Os sujeitos da pesquisa citaram mais aspectos positivos que negativos durantes suas respostas, demonstrando existir vários pontos proveitosos em ser habitante do munícipio. Entretanto, os aspectos que mais agradam aos sujeitos da pesquisa são os pontos turísticos, mas por outro lado, é importante notar como isso influência no cotidiano dos moradores de uma forma negativa também, já que o turismo acaba elevando o custo de vida para seus moradores, e mesmo colaborando para haver, historicamente, uma maior preocupação do poder público com a paisagem e as condições socioambientais das áreas mais valorizadas, em detrimento dos bairros periféricos, o que aumenta as desigualdades socioespaciais.

A percepção de estar em uma localidade onde a população e a paisagem são agradáveis é essencial para a satisfação do turista em visita ao centro receptor, assim como para o cotidiano dos moradores. Neste contexto, Yázigi (1999, p.134) cita que “a paisagem interessa antes a seus próprios habitantes, e que só numa relação de estima, deles com ela, é que despertará o interesse de transeuntes, visitantes e turistas". Todavia, é notório o contraste nas condições paisagísticas e na qualidade de vida entre os diversos setores da cidade de Poços de Caldas, o que desfavorece a consolidação da atividade turística e o bem estar dos moradores em algumas áreas do espaço urbano local.

\section{REFERÊNCIAS}

ANDRADE, Alexandre Carvalho de. Paisagem e qualidade de vida em localidades turísticas: o caso de Poços de Caldas, Minas Gerais, Brasil, 2005, 188 f. Dissertação (Mestrado em Geografia) - Programa de Pós-Graduação em Geografia, UNESP, Rio Claro SP.

BRAVO, Maria Teresa Delgado de. Ciudades medias, planificación urbana y calidad de vida. Revista Geográfica Venezolana, vol. 38 n² 2, p. 153-164, abr. 1997.

BRAVO, Maria Teresa Delgado de; VERA, Silvia Failache de. El concepto de calidad de vida: una revisión de su alcance y contenido. Revista Geográfica Venezolana vol. 34 n ${ }^{\circ}$ 2. Mérida: Instituto de Geografia, p. 275 - 295, 1993.

CARLOS, Ana Fani Alessandri. A cidade. São Paulo: ed. Contexto, 1994. 
SOCIEDADE E

TERRITÓRIO
ANDRADE, Alexandre Carvalho de

RAMOS, Giovanna Moraes

MARTINS, Raphael Miranda

. O lugar no/do mundo. São Paulo: FFLCH/USP, 2007.

CRUZ, Rita de Cássia Ariza da. As paisagens artificiais criadas pelo turismo. YÁZIGI, Eduardo (org). Turismo e Paisagem. São Paulo: ed. Contexto, 2002. p 107-119.

ESPINO, Emma Pérez-Chacón. Paisaje y turismo. Congreso de Ciencia del Paisaje, 3, Barcelona. Anais... Barcelona: Universidad de Barcelona, 1999. p. 77-83.

GERARDI, Lúcia Helena de Oliveira; SILVA, Bárbara-Christine Nentwig Silva. Quantificação em Geografia. São Paulo: Dífel, 1981.

GÜELL, José Miguel Fernández. Planificación estratégica de ciudades. Barcelona: Gustavo Gili S/A, 1997.

LYNCH, Kevin. A imagem da cidade. São Paulo: Martins Fontes, 1960.

OLIVEIRA, Elias Mendes. Produção do espaço urbano em Poços de Caldas (MG). Caminhos de Geografia, v. 15, n. 50, p. 100-113, jun. 2014.

OLIVEIRA, Lívia de. Que é Geografia. Sociedade e natureza, vol.11 n. 21-22, p. 89-95, dez. 1999.

PEREIRA Érico Felden, TEIXEIRA Clarissa Stefani, SANTOS, Anderlei dos. Qualidade de vida: abordagens, conceitos e avaliação. Revista Brasileira de Educação Física e Esporte, v.26, n.2, p. 241-250, jun. 2012.

PIRES, Paulo dos Santos. A paisagem rural como recurso turístico. RODRIGUES, Adyr Balastreri (org). Turismo rural. São Paulo: ed. Contexto, 2001. p. 117-132.

PUJADAS, Romà; FONT, Jaume. Ordenación y planificación territorial. Madrid: Síntesis, 1999.

SANTOS, Milton. A natureza do espaço. Técnica e tempo, razão e emoção. São Paulo: Hucitec, 1996.

SERPA, Ângelo. A paisagem periférica. In: YÁZIGI, E. (org.). Turismo e paisagem. São Paulo: Contexto, 2002. pp. 133-147.

SILVA, Eduardo de Araújo da. Segregação socioespacial em Poços de Caldas (MG). 2018, 70f. Monografia (Licenciatura em Geografia) - Curso de Geografia, IFSULDEMINAS, Poços de Caldas - MG.

SOUZA, Marcelo Lopes de. Mudar a cidade. Rio de Janeiro: Bertrand Brasil, 2002.

Brasil, 2011. ABC do desenvolvimento urbano. Rio de Janeiro: Bertrand 
SPOSITO, Eliseu Savério. Redes e cidades. São Paulo: Edunesp, 2008.

YÁZIGI, Eduardo. Vandalismo, paisagem e turismo no Brasil. In: YÁZIGI, Eduardo; CARLOS, Ana Fani Alessandri; CRUZ, Rita de Cássia Ariza da (org.). Turismo: Espaço, Paisagem e Cultura. São Paulo: Hucitec, 1999. p. 133-155.

Civilização urbana, planejamento e turismo. São Paulo: Contexto, 2003.

Recebido em Setembro de 2019

Aprovado em Dezembro de 2019

Publicado em Dezembro de 2019 